Check for updates

Cite this: RSC Adv., 2019, 9, 40286

Received 25th October 2019

Accepted 25th November 2019

DOI: 10.1039/c9ra08763j

rsc.li/rsc-advances

\title{
Preparation and electroactive phase adjustment of Ag-doped poly(vinylidene fluoride) (PVDF) films $\uparrow$
}

\author{
Seung-Hyun Kim, ${ }^{\text {ab }}$ So-Jeong Park, ${ }^{a}$ Chang-Yeol Cho, ${ }^{a}$ Hong Suk Kang, (D) a \\ Eun-Ho Sohn, (D) ${ }^{a}$ In Jun Park, ${ }^{a}$ Jong-Wook Ha ${ }^{a}$ and Sang Goo Lee (D) *a
}

The crystallinities of Ag-doped poly(vinylidene fluoride) (PVDF) films were modified by removing $\mathrm{Ag}^{+}$using a novel washing process, which allowed control of the ratio of $\gamma$ - and $\beta$-phases. The polarity of the composite film without $\mathrm{Ag}^{+}$removal through the washing process reached $98 \%$, and the $\beta$-phase content in the total electroactive phase was increased to $61 \%$, according to Fourier-transform infrared spectroscopy. When $\mathrm{Ag}^{+}$were removed through a process involving several cycles of washing, filtering, drying, and re-dissolving, the highest ratio of the $\gamma$-phase was increased to $67 \%, 28 \%$ higher than that before washing. This showed that $\mathrm{Ag}^{+}$induced $\beta$-phase formation while Ag nanoparticles induced $\gamma^{-}$ phase formation, and that the ratio of $\gamma$ - and $\beta$-phases in PVDF composite films can be controlled to suit specific applications by this washing process.

\section{Introduction}

Extensive research has been conducted over the last few years on the development of high-performance energy harvesters for various applications, including self-powered sensors, smart skins, wearable electronics and portable electronics. ${ }^{\mathbf{1 - 3}}$ Inorganic materials with high piezoelectric coefficients, such as $\mathrm{BaTiO}_{3}, \mathrm{PbZr}_{x} \mathrm{Ti}_{1-x} \mathrm{O}_{3}(\mathrm{PZT}), \mathrm{ZnO}, \mathrm{ZnSnO}_{3}$, and $\mathrm{GaN}$, have attracted attention because they possess nanostructures that facilitate electricity harvesting from mechanical energy. ${ }^{\mathbf{4 - 1 2}}$ However, the rigidity, brittleness, processing difficulties, and toxicity of these materials have limited their possible applications. ${ }^{13-17}$

Polymer-based materials, on the other hand, are lightweight, flexible, and easy to process. Poly(vinylidene fluoride) (PVDF) is attractive because of its excellent pyro-, piezo-, and ferroelectricities. ${ }^{18-21}$ Moreover, flexibility, light weightness, easy processing, and presence of five crystallite phases $(\alpha, \beta, \gamma, \delta$, and $\varepsilon)^{22-25}$ impart excellent mechanical properties, high thermal and chemical stabilities, and biocompatibility to PVDF. ${ }^{26-29}$ The polar $\beta$ - and $\gamma$-forms are facilitate electrical applications.

\footnotetext{
${ }^{a}$ Interface Materials and Chemical Engineering Research Center, Korea Research Institute of Chemical Technology, Daejeon, 34114, Republic of Korea. E-mail: sgoo@ krict.re.kr

${ }^{b}$ School of Chemical Engineering, Sungkyunkwan University, Suwon 16419, Republic of Korea

$\dagger$ Electronic supplementary information (ESI) available: Additional data for the FT-IR spectra of $\mathrm{Ag}^{+} / \mathrm{AgNP} / \mathrm{PVDF}$ composite film according to the amount of hydrazine (Fig. S1), the melting enthalpy $\left(\Delta H_{\mathrm{f}}\right)$ and total crystallinity $\left(X_{\mathrm{c}}\right)$ of PVDF films (Table S1), and XRD patterns and their curve deconvolution (Fig. S2) in the literature (PDF). See DOI: 10.1039/c9ra08763j
}

Among the crystalizes polar phases with piezoelectric effect can be easily formed by external treatment such as stretching, heat treatment and poling (applying a high electric field) and crystalline induction of the film due to mixing with filler such as nanoparticles have. ${ }^{\mathbf{2 6 , 3 0 - 3 2}}$ However, the crystallization induction of the film through an external treatment method has a disadvantage that it can induce an undesirable structural transformation and an incomplete crystal phase. ${ }^{33,34}$ Conversely, nanocomposite film formation of nano-fillers and PVDF can meet the requirements of device fabrication because it not only promotes the formation of polar phases in PVDF, but also improves the mechanical properties. Typically, different types of inorganic fillers are doped in PVDF to induce electroactive phases and improve electrical and mechanical properties.

Current methods for inducing crystalline polar phases with the piezoelectric effect in PVDF include stretching, heat treatment, poling, and addition of nanoparticle (NP) fillers to the PVDF matrix. ${ }^{26,30-32}$ While most of these methods can induce undesirable structural transformations and incomplete phases, the addition of NPs to PVDF promotes polar phase formation and improves mechanical properties. ${ }^{33,34}$ AgNPs have been widely studied as additives because of their high electrical and thermal conductivity, excellent catalytic activity in oxidation and reduction systems, effective anti-bacterial/anti-fouling action, and relatively low cost. ${ }^{35-38}$ However, the piezoelectric characteristics of AgNP/PVDF composite films depend on their electroactive phase composition, which is difficult to control using current manufacturing methods.

The aim of this study was to change the crystallinity of $\mathrm{Ag}^{+} /$ AgNP/PVDF composite films by removing $\mathrm{Ag}^{+}$through a new washing process and consequently control the ratio of $\gamma$ - and $\beta$ phases. Compared to the afore-mentioned physical methods for 
modifying crystallinity, washing has not been well-studied or standardized. Herein, a washing process is outlined that allows for the removal of $\mathrm{Ag}^{+}$from $\mathrm{Ag}^{+} / \mathrm{AgNP} / \mathrm{PVDF}$ composite films to increase the ratio of the $\gamma$-phase.

\section{Results and discussion}

Studies on electroactive phase formation in PVDF nanocomposite films are mainly performed through FTIR spectroscopy, in which electroactive phases yield peaks at $840 \mathrm{~cm}^{-1} \cdot{ }^{39} \mathrm{In}$ addition, $\beta$-phase induction using AgNPs was reportedly effective in inducing electroactive phase formation in PVDF. ${ }^{\mathbf{4 0}}$ However, when PVDF and $\mathrm{AgNO}_{3}$ are mixed for the formation of the PVDF/AgNP composite, and the electroactive phase is induced through film production, unreacted $\mathrm{Ag}^{+}$remains, as shown in Fig. 1(a). The remaining $\mathrm{Ag}^{+}$reacts with PVDF separately from AgNPs, thus affecting the electroactive phase induction of PVDF. To confirm this, the properties of the prepared $\mathrm{Ag}^{+} / \mathrm{AgNP} / \mathrm{PVDF}$ films were studied. $\mathrm{Ag}^{+}$and $\mathrm{AgNPs}$ are uniformly distributed in the prepared $\mathrm{Ag}^{+} / \mathrm{AgNP} / \mathrm{PVDF}$ film, as shown in Fig. 1(b and c). The electroactive phase of PVDF is formed by PVDF-AgNP interaction; as the amount of $\mathrm{Ag}$ is increased, the reaction between PVDF and $\mathrm{Ag}$ is increased. Therefore, the electroactive phase content and melting temperature $T_{\mathrm{m}}$ are increased with increasing $\mathrm{Ag}$, as shown in Fig. 1(d). In addition, the AgNPs and $\mathrm{Ag}^{+}$induce electroactive phase formation in PVDF. As shown in Fig. 1(e), pure PVDF films prepared at $10 \mathrm{wt} \%$ and $80{ }^{\circ} \mathrm{C}$ show peaks at $975,795,764$, and $614 \mathrm{~cm}^{-1}$ due to the $\alpha$-phase. As the amount of $\mathrm{Ag}$ precursor is increased, these $\alpha$-phase peaks disappear because of AgNPPVDF and $\mathrm{Ag}^{+}-$PVDF interactions; instead, peaks at 840, 1233, and $1275 \mathrm{~cm}^{-1}$ from the polar $\beta$-and $\gamma$-phases appear. PVDF also has different melting points depending on the phase in which it exists. ${ }^{41}$ Pure PVDF has $\alpha$ - and $\gamma$-phases, and for these phases the peaks appear around $167^{\circ} \mathrm{C}$ and $174{ }^{\circ} \mathrm{C}$ (Fig. 1(d)). Upon increasing the amount of $\mathrm{Ag}$, the $\alpha$-phase disappears and the $\gamma$-and $\beta$-phases emerge. The peaks appearing at $165^{\circ} \mathrm{C}$ and $174{ }^{\circ} \mathrm{C}$ correspond to the $\gamma$ - and $\beta$-phases. AgNPs and $\mathrm{Ag}^{+}$tend to induce $\gamma$ - and $\beta$-phase formation respectively. The peak corresponding to the $\beta$-phase appears with a polar solvent from hydrogen bonds between the PVDF chains and the $\mathrm{F}$ bridging $\mathrm{AgNO}_{3}$ and the PVDF chain. ${ }^{42}$ The $\gamma$-phase, meanwhile, is induced when the surface charges of AgNPs cause vibrational motion through electrostatic coupling between PVDF dipoles. Some parts of the PVDF polymer experience a polar induction from the reaction between the negative charge on the AgNP surface and the $\delta^{+}$, generated around the $\mathrm{H}$ atom of PVDF. However, the degree of polarity of the affected parts does not
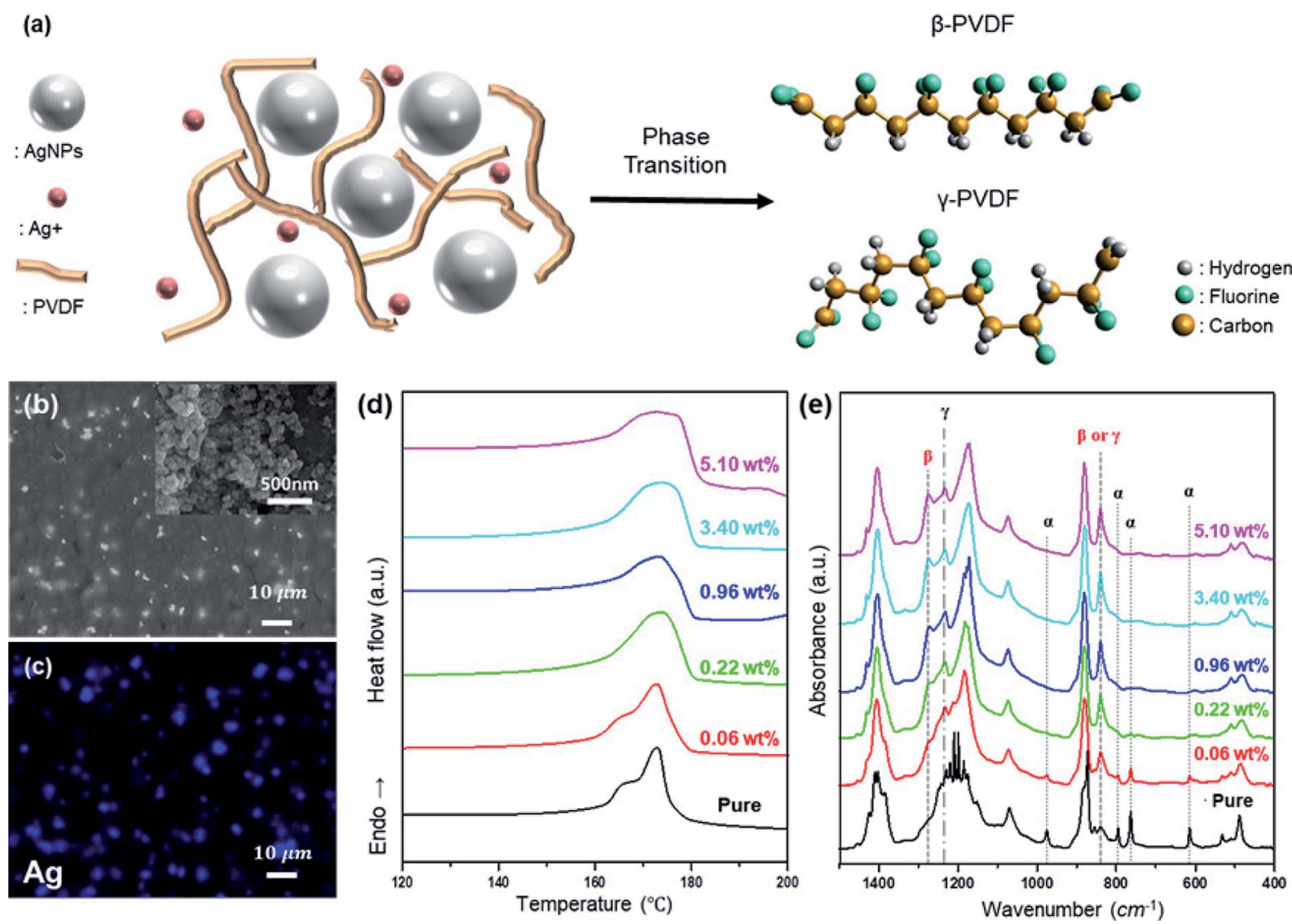

Fig. 1 Preparation and analysis of $\mathrm{Ag}^{+} / \mathrm{AgNP} / \mathrm{PVDF}$ composite film. (a) Schematic of $\mathrm{Ag}^{+} / \mathrm{AgNP} / \mathrm{PVDF}$ composite film preparation. (b) SEM images (Insets show the SEM images of AgNPs), (c) EDS element mapping images of Ag atoms, (d) DSC melting endotherms, and (e) FT-IR spectra of Ag ${ }^{+} /$ AgNP/PVDF composite films. 
affect the rest of the polymer chain, leading to a $\gamma$-phase in the form of $\mathrm{T}_{3} \mathrm{GT}_{3} \mathrm{G}^{\prime}$. $^{43}$

As the amount of $\mathrm{Ag}$ precursor $\left(\mathrm{AgNO}_{3}\right)$ increases, so does the quantity of unreacted $\mathrm{Ag}^{+}$. Therefore, in comparing $\mathrm{Ag} \mathrm{0.96}$, 3.40 , and $5.10 \%$, the total polar phases are similar, but as the amount of precursor increases, the peak at $1275 \mathrm{~cm}^{-1}$ representing the $\beta$-phase is heightened. Increasing the amount of hydrazine fraction of $\mathrm{Ag}^{+}$reduction is also increased and thus the amount of AgNPs. As a result, the $\beta$-phase is decreased and the $\gamma$-phase is increased as shown in Fig. S1. $\dagger$

The modification of the PVDF electroactive phase to $\gamma$-phase is achieved through washing, as shown in Fig. 2(a). As shown in Fig. 2(b and c), the AgNP/PVDF composite films are formed such that AgNPs are uniformly distributed in the PVDF. These films lack the $\mathrm{Ag}^{+}-\mathrm{PVDF}$ interactions described above. Therefore, as AgNP concentration is increased, the electroactive phase induction of PVDF by AgNPs is increased, and the electroactive phase is also increased only up to a certain concentration. However, since excess AgNPs interfere with the reaction between the adjacent AgNPs and PVDF, the total percentage of the polar phase is decreased. ${ }^{\mathbf{4 4 , 4 5}}$ As a result, the film $T_{\mathrm{m}}$ increases until $0.96 \mathrm{wt} \%$, as shown in Fig. 2(d), but decreases again starting from $3.4 \mathrm{wt} \%$. As shown in Fig. 2(b), $\alpha$-phase is predominant until $0.06 \mathrm{wt} \%$, but after $0.22 \mathrm{wt} \%, \gamma$-phase is generated and $\alpha$-phase is decreased. Therefore, the $T_{\mathrm{m}}$ of the film is increased, and is highest at $0.96 \mathrm{wt} \%$ with the highest $\gamma$ phase. $T_{\mathrm{m}}$ decreases from $3.4 \mathrm{wt} \%$ because of the predominance of the $\alpha$-phase.

Unlike $\mathrm{Ag}^{+}$, AgNPs induce $\gamma$-phase formation in PVDF. As shown in Fig. 1(e), when the Ag concentration is increased, the peaks at $975,795,764$, and $614 \mathrm{~cm}^{-1}$ from the $\alpha$-phase are diminished, and peaks at 1233 and $1275 \mathrm{~cm}^{-1}$ appear from the polar phase. However, as shown in Fig. 2(e), when $\mathrm{Ag}^{+}$is removed and only AgNPs are present, peaks at 975, 795, 764, and $614 \mathrm{~cm}^{-1}$ from the $\alpha$-phase are decreased with increasing $\mathrm{Ag}$ concentration, and the peak at $1235 \mathrm{~cm}^{-1}$ from the $\gamma$-phase is increased. These results demonstrate that $\mathrm{Ag}^{+}$induces $\beta$ phase formation and that of the polar phase composition of PVDF can be controlled.

Data analysis using XRD was also performed to confirm the control over the polar phase ratio of PVDF. As shown in Fig. S2(a and b), $\uparrow$ the Ag/PVDF composite film before the washing process had a peak of $18.5^{\circ}$ corresponding to the $\gamma$ (202) plane and broad peaks at $20.2^{\circ}$ and $20.5^{\circ}$ corresponding to the $\beta$ (110) and (110/200) planes. However, after washing, only peaks at $18.5^{\circ}$ and $20.2^{\circ}$ appeared, as shown in Fig. S2(c and d). $\dagger$ The peak at $38.5^{\circ}$ indicated the presence of AgNPs.

The crystallinity $\left(X_{\mathrm{c}}\right)$ in the Ag/PVDF composite film can be quantitatively calculated using the following equation, ${ }^{46}$

(a)
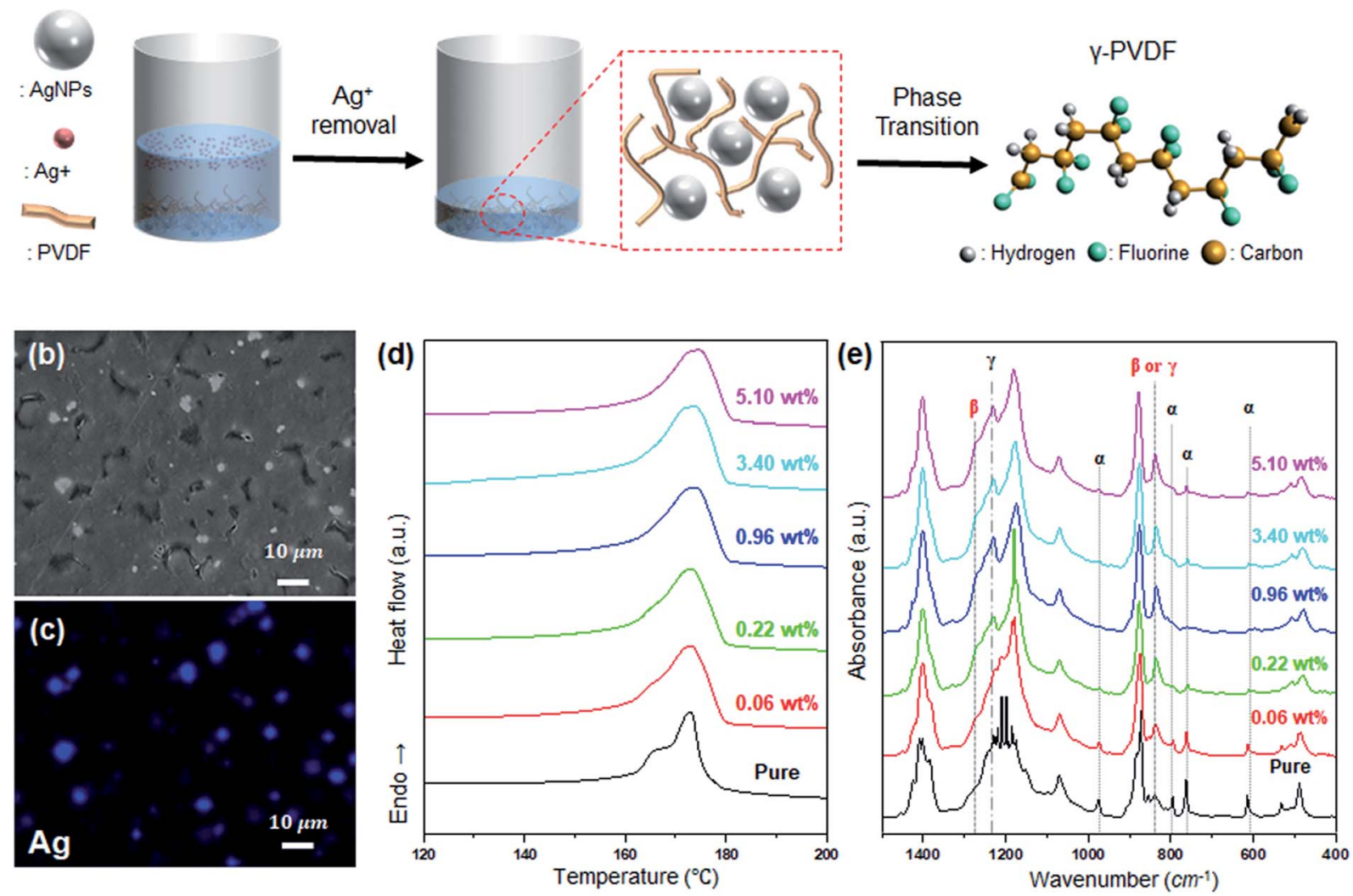

Fig. 2 Preparation and analysis of AgNP/PVDF composite film. (a) Schematic of AgNP/PVDF composite film preparation. (b) SEM images, (c) EDS element mapping images of Ag atoms, (d) DSC melting endotherms and (e) FT-IR spectra of AgNP/PVDF composite films. 


$$
X_{\mathrm{c}}=\frac{\Delta H_{\mathrm{f}}}{\Delta H_{\mathrm{f}}^{*}} \times 100 \%
$$

where $\Delta H_{\mathrm{f}}^{*}$ and $\Delta H_{\mathrm{f}}$ are the enthalpy of melting for $100 \%$ crystalline PVDF (104.7 $\mathrm{J} \mathrm{g}^{-1}$ ) and the Ag/PVDF composite film, respectively. The crystallinity of the pure PVDF film is $41.67 \%$, while the crystallinity of Ag/PVDF composite films slightly increases (refer Table S1 $\dagger$ ). After washing the films, the AgNP/ PVDF film showed the highest crystallinity of $42.71 \%$ at $5.10 \mathrm{wt} \%$ whereas the $\mathrm{Ag}^{+} / \mathrm{AgNP} / \mathrm{PVDF}$ film with both $\gamma$ - and $\beta$ phases before washing also showed a maximum crystallinity of $43.33 \%$ at $5.10 \mathrm{wt} \%$. This indicates that not only the $\gamma$ - and $\beta$ phases of the film increased, but also the total crystallinity slightly increased.

Data analysis using XRD was also performed to confirm the control over the polar phase ratio of PVDF. As shown in Fig. S2(a and $b), \dagger$ the $\mathrm{Ag} / \mathrm{PVDF}$ composite film before the washing process had a peak of $18.5^{\circ}$ corresponding to the $\gamma(202)$ plane and broad peaks at $20.2^{\circ}$ and $20.5^{\circ}$ corresponding to the $\beta(110)$ and $(110 / 200)$ planes. However, after washing, only peaks at $18.5^{\circ}$ and $20.2^{\circ}$ appeared, as shown in Fig. S2(c and d). $\dagger$ The peak at $38.5^{\circ}$ indicated the presence of AgNPs.

As shown by the ICP data in Fig. 3, the washing process removes unreacted $\mathrm{Ag}^{+}$, reducing the $\mathrm{Ag}^{+}$concentration in the

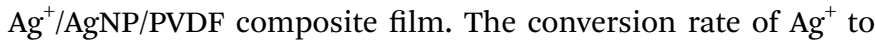
AgNPs is calculated by the $\mathrm{Ag}$ wt\% value present in the sample before and after washing. These values are 37, 31.5, 82.4, 85, and $89.7 \%$ for $0.06,0.22,0.96,3.40$, and $5.10 \mathrm{wt} \% \mathrm{AgNO}_{3}$, respectively. As the concentration of $\mathrm{AgNO}_{3}$ in the sample is increased, the amount of $\mathrm{Ag}^{+}$that can be converted into AgNPs is also increased, thus increasing the $\mathrm{Ag}^{+}-\mathrm{AgNP}$ conversion.

The fractions of the electroactive phase $(\beta+\gamma)$ in the PVDF composite film can be quantitatively calculated using the following equation: ${ }^{47}$

$$
F_{(\beta, \gamma)}=\frac{X_{\beta, \gamma}}{X_{\alpha}+X_{\beta, \gamma}}=\frac{A_{\beta, \gamma}}{\left(\frac{K_{840}}{K_{763}}\right) A_{\alpha}+A_{\beta, \gamma}}
$$

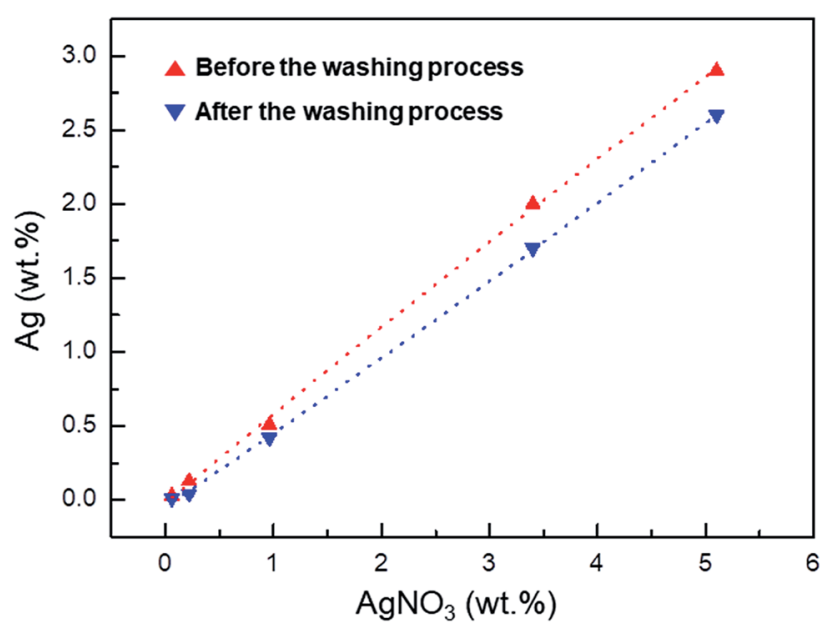

Fig. 3 Inductively coupled plasma (ICP) data of Ag atoms in films with $0.06,0.22,0.96,3.40$, and $9.10 \mathrm{wt} \% \mathrm{AgNO}_{3}$ affected by the washing process where $X$ is the crystalline mass fraction, $A$ is the absorbance of specific peaks ( $\alpha$ shows an absorbance peak at $764 \mathrm{~cm}^{-1}$ and $\beta+$ $\gamma$ shows a peak at $840 \mathrm{~cm}^{-1}$ ), and $K_{840}$ and $K_{763}$ are the absorption coefficients at the respective wavenumbers with values of $7.7 \times$ $10^{4}$ and $6.1 \times 10^{4} \mathrm{~cm}^{2} \mathrm{~mol}^{-1}$, respectively. The fractions of $(\beta+\gamma)$ in the PVDF composite films according to eqn (2) are plotted in Fig. 4(a). These results indicate that for the $\mathrm{Ag}^{+} / \mathrm{AgNP} / \mathrm{PVDF}$ composite films, the highest fraction of the electroactive phase is increased from $55 \%$ to $90 \%$ as the amount of $\mathrm{AgNO}_{3}$ is increased from $0.06 \mathrm{wt} \%$ to $0.22 \mathrm{wt} \%$. As the amount of $\mathrm{AgNO}_{3}$ is increased from 0.22 to $5.10 \mathrm{wt} \%$, the fraction of the electroactive phase remains almost constant, reaching a maximum value of $99 \%$. In contrast, for the AgNP/PVDF film, the fraction of the electroactive phase of PVDF is increased more significantly with increasing $\mathrm{AgNO}_{3}$ than that for $\mathrm{Ag}^{+} / \mathrm{AgNP} / \mathrm{PVDF}$. In addition, the amount of the electroactive phase in PVDF is gradually increased to $86 \%$ until the amount of $\mathrm{AgNO}_{3}$ reaches $0.96 \mathrm{wt} \%$. However, as $\mathrm{AgNO}_{3}$ is increased from $0.96 \mathrm{wt} \%$ to $5.10 \mathrm{wt} \%$, the value of the electroactive phase is gradually decreased to $80 \%$. These results confirm that $\mathrm{Ag}^{+}$and AgNPs are highly effective in inducing electroactive phase formation in PVDF.

The fractions of the electroactive phase were calculated using the absorbance of the peak at $840 \mathrm{~cm}^{-1}$. However, this peak reflects both $\beta$ - and $\gamma$-phases. To confirm the effect of $\mathrm{Ag}^{+}$ on $\beta$ phase induction, quantitative values of $\beta$ - and $\gamma$-phases were needed. The quantification of individual $\beta$ - and $\gamma$-phases was performed using the absorbance of the two peaks (1275 and $1234 \mathrm{~cm}^{-1}$ ) and the following equation:

$$
\frac{A_{\beta}}{A_{\gamma}}=\frac{H_{1275}}{H_{1234}}
$$

where $A_{\beta}$ and $A_{\gamma}$ are the absorbance of peaks at 1275 and $1234 \mathrm{~cm}^{-1}$, respectively. For the $\mathrm{Ag}^{+} / \mathrm{AgNP} / \mathrm{PVDF}$ composite film, $A_{\gamma}>A_{\beta}$ from $0.06 \mathrm{wt} \%$ to $0.96 \mathrm{wt} \%$ of $\mathrm{AgNO}_{3}$, as shown in Fig. 4(b). However, as the amount of $\mathrm{AgNO}_{3}$ is increased from 0.96 to $5.10 \mathrm{wt} \%, A_{\beta}>A_{\gamma}$ because $\mathrm{Ag}^{+}$induce $\beta$-phase formation. The highest ratio of the $\beta$-phase in the total polar phase is $61 \%$. Meanwhile, for the AgNP/PVDF composite film, $A_{\gamma}>A_{\beta}$ for all $\mathrm{AgNO}_{3}$ weight fractions. Additionally, as the concentration of $\mathrm{AgNO}_{3}$ is increased, $A_{\gamma}$ is increased but $A_{\beta}$ is not. The ratio of the $\gamma$-phase in the total polar phase is increased to $67 \%, 28 \%$ higher than that before the washing process. These results indicate that, in AgNP/PVDF composite films, the ratio of $\beta$ - and $\gamma$ phases in the electroactive phase can be controlled using the washing process described here; $\mathrm{Ag}^{+}$supports $\beta$-phase while AgNPs induce $\gamma$-phase.

\section{Experimental}

\section{Materials}

The PVDF polymer was Solef® 6008 (Solvay Solexis) and the solvent was $N, N$-dimethylformamide (DMF, Sigma-Aldrich, USA). $\mathrm{AgNO}_{3}$ (Sigma-Aldrich, USA) was used as an $\mathrm{Ag}^{+} / \mathrm{AgNP}$ precursor. Hydrazine monohydrate $\left(\mathrm{NH}_{2} \mathrm{NH}_{2} \cdot \mathrm{H}_{2} \mathrm{O}\right.$, Junsei Chemical, Japan), in the same molar ratio as $\mathrm{AgNO}_{3}$, was added as a reducing agent to the $\mathrm{DMF} / \mathrm{PVDF} / \mathrm{AgNO}_{3}$ system to reduce $\mathrm{Ag}^{+}$to AgNPs. 

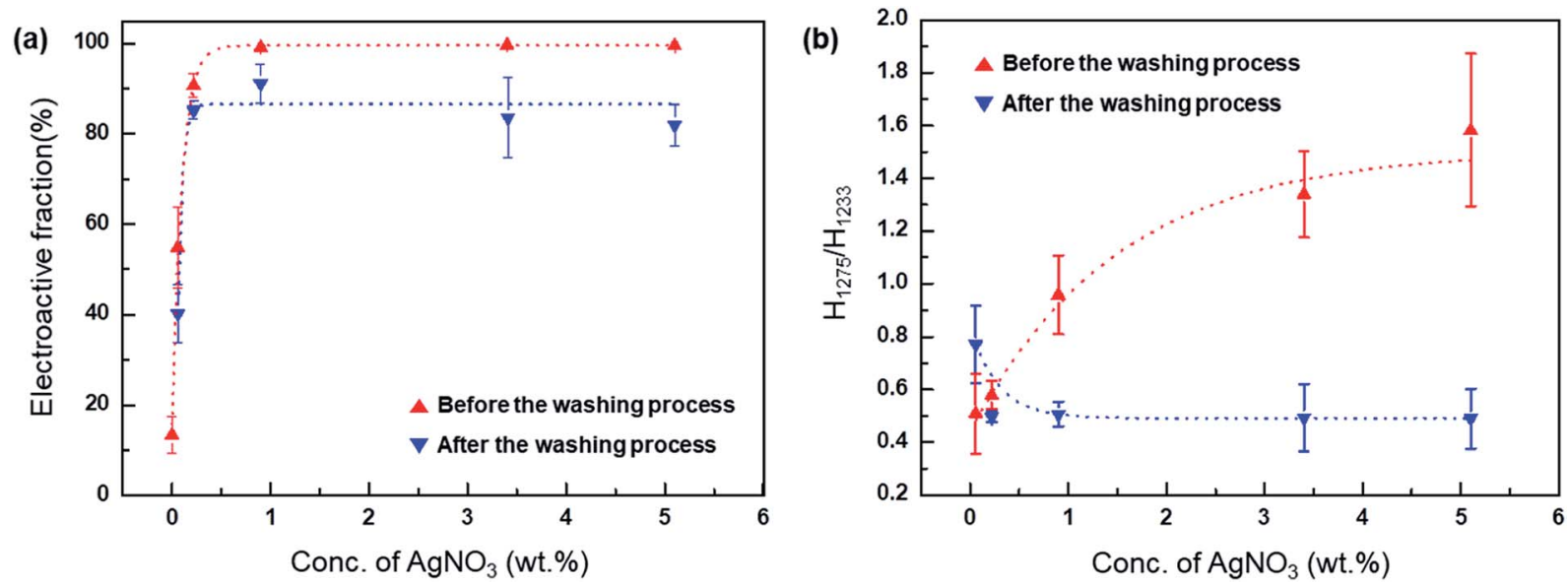

Fig. 4 (a) Electroactive fractions of films with 0.06, 0.22, 0.96, 3.40, and $9.10 \mathrm{wt} \% \mathrm{AgNO}_{3}$, as measured before and after washing process. (b) Ratio of $\beta$ - to $\gamma$-phases $\left(H_{1275} / H_{1233}\right)$ as a function of $\mathrm{AgNO}_{3}$ contents in AgNP/PVDF composites films.

\section{Methods}

Preparation of $\mathbf{A g}^{+} / \mathbf{A g N P} / \mathbf{P V D F}$ solution. PVDF was dissolved in DMF for $4 \mathrm{~h}$ at $60^{\circ} \mathrm{C}$ to prepare a $10 \mathrm{wt} \%$ solution, and cooled to room temperature to which $\mathrm{AgNO}_{3}$ solution at different concentrations were mixed. To determine the effect of $\mathrm{AgNO}_{3}$ concentration, $\mathrm{AgNO}_{3}$ solutions of concentrations 0.06, 0.22, $0.96,3.40$, and $5.10 \mathrm{wt} \%$ were formed and stirred at a constant speed for $10 \mathrm{~min}$. Then, hydrazine was added to the solution in the same molar ratio as $\mathrm{AgNO}_{3}$ and reacted for $3 \mathrm{~h}$ to prepare an AgNP/PVDF composite.

Half of each reaction solution was dried in a vacuum oven at $80{ }^{\circ} \mathrm{C}$ for $24 \mathrm{~h}$; this portion was used to form $\mathrm{Ag}^{+} / \mathrm{AgNP} / \mathrm{PVDF}$ films. The remaining half was subjected to a washing process to remove $\mathrm{Ag}^{+}$and form AgNP/PVDF composite films. The solution was washed three times in triple distilled water. In this process, the reaction solution was precipitated in water, stirred for $1 \mathrm{~h}$, filtered, and dried in a vacuum oven at $80^{\circ} \mathrm{C}$ for $24 \mathrm{~h}$ followed by re-dissolution in DMF. The washing-precipitationre-dissolution procedure was repeated five times for each reaction solution. Finally, the unwashed and washed samples were dissolved in DMF to prepare $10 \mathrm{wt} \%$ casting solutions of equal concentrations.

Preparation of $\mathrm{AgNO}_{3} / \mathrm{AgNP} / \mathrm{PVDF}$ and $\mathrm{AgNP} / \mathrm{PVDF}$ composite films. A section of polyethylene terephthalate (PET) film $\left(7 \times 21 \mathrm{~cm}^{2}\right)$ was heated to $80{ }^{\circ} \mathrm{C}$ and fixed to prevent movement during casting. The prepared unwashed casting solution of $\mathrm{AgNO}_{3} / \mathrm{AgNP} / \mathrm{PVDF}(2.0 \mathrm{~mL})$ was coated onto the PET film and dried for $5 \mathrm{~min}$ at $80{ }^{\circ} \mathrm{C}$ before $6 \mathrm{~h}$ drying in a convection oven at $80{ }^{\circ} \mathrm{C}$ to remove the remaining solvent. This process was repeated for each concentration of washed and unwashed AgNPs/PVDF casting solution to obtain 11 total film samples.

\section{Characterization}

The crystalline phases of PVDF were identified by Fouriertransform infrared spectroscopy (FT-IR, Bruker ALPHA-T \& ALPHA-P). The film morphologies were investigated by field- emission scanning electron microscopy (FE-SEM, TESCAN Mira 3 LMU FEG) and energy dispersive spectroscopy (EDS, Bruker Quantax 200). Inductively coupled plasma-atomic emission spectroscopy (ICP-AES, Thermo Fisher Scientific iCAP 6500Duo) was conducted to determine the relative amount of $\mathrm{Ag}^{+}$to NP conversions before and after washing. A differential scanning calorimeter (DSC, Q1000 V9.9 Build 303) was calibrated with in before use and calorimetry was performed in $\mathrm{N}_{2}$ atmosphere. The films were heated at $5^{\circ} \mathrm{C} \min ^{-1}$ from 0 to $220{ }^{\circ} \mathrm{C}$.

\section{Conclusion}

Polar crystal phase formation was induced in PVDF through the preparation of PVDF composite films with $\mathrm{Ag}^{+}$and AgNPs. In addition, the concentrations of $\beta$ - and $\gamma$-phases were controlled using a novel washing process. The polarity of the $\mathrm{Ag}^{+} / \mathrm{AgNP} /$ PVDF composite film before washing reached $98 \%$, and the ratio of the $\beta$ phase was $61 \%$. The polarity of the composite film after washing was $85 \%$, lower than that before washing. However, of the total polar phase of PVDF, the ratio of the $\beta$ phase was decreased and the ratio of the $\gamma$-phase was increased to $67 \%$, demonstrating the ability of $\mathrm{Ag}^{+}$and AgNPs to induce $\beta$ - and $\gamma$-phase formation, respectively. These results indicated that the polar phase and, thus, polarity of PVDF can be easily adjusted, thereby promoting various applications such as outdoor energy harvesting, self-powered wearable devices, and portable sensors.

\section{Conflicts of interest}

The authors declare no competing financial interest.

\section{Acknowledgements}

This research is supported by the Korea Institute of Energy Technology Evaluation and Planning (KETEP) grant funded by 
the Korea Government Ministry of Trade, Industry and Energy (grant no. 201720104830).

\section{References}

1 U. Yaqoob, A. S. M. I. Uddin and G.-S. Chung, Appl. Surf. Sci., 2017, 405, 420-426.

2 C. Sun, J. Shi and X. Wang, J. Appl. Phys., 2010, 108, 034309034320.

3 J. H. Jung, M. Lee, J. I. Hong, Y. Ding, C. Y. Chen, L. J. Chou and Z. L. Wang, ACS Nano, 2011, 5, 10041-10046.

4 Z. L. Wang and J. Song, Science, 2006, 312, 242-246.

5 M. Koo, K.-I. Park, S. H. Lee, M. Suh, D. Y. Jeon, J. W. Choi, K. Kang and K. J. Lee, Nano Lett., 2012, 12, 4810-4816.

6 S. Kim, H. Y. Jeong, S. K. Kim, S. -Y. Choi and K. J. Lee, Nano Lett., 2011, 11, 5438-5442.

7 K.-I. Park, C. K. Jeong, J. Ryu, G.-T. Hwang and K. J. Lee, Adv. Energy Mater., 2013, 3, 1539-1544.

8 P. Adhikary, A. Biswas and D. Mandal, Nanotechnology, 2016, 27, 495501.

9 M. M. Alam, S. K. Ghosh, A. Sultana and D. Mandal, Nanotechnology, 2015, 26, 165403.

10 A. Sultana, M. M. Alam, S. Garain, T. K. Sinha, T. R. Middya and D. Mandal, ACS Appl. Mater. Interfaces, 2015, 7, 1909119097.

11 M. M. Alam and D. Mandal, ACS Appl. Mater. Interfaces, 2016, 8, 1555-1558.

12 T. Q. Trung and N.-E. Lee, Adv. Mater., 2016, 28, 4338-4472.

13 C. S. Lee, J. Joo, S. Han and S. K. Koh, Appl. Phys. Lett., 2004, 85, 1841-1843.

14 C. S. Lee, J. Joo, S. Han, J. H. Lee and S. K. Koh, Synth. Met., 2005, 152, 49-52.

15 M. M. Alam, A. Sultana, D. Sarkar and D. Mandal, Nanotechnology, 2017, 28, 365401.

16 S. Jana, S. Garain, S. Sen and D. Mandal, Phys. Chem. Chem. Phys., 2015, 17, 17429-17436.

17 Y. N. Hao, X. H. Wang, S. O'Brien, J. Lombardi and L. T. Li, J. Mater. Chem. C, 2015, 3, 9740-9747.

18 A. Vinogradov and F. Holloway, Ferroelectrics, 1999, 226, 169-181.

19 B. Ameduri, Chem.-Eur. J., 2018, 24, 18830-18841.

20 J. Gomes, J. S. Nunes, V. Sencadas and S. Lanceros-Mendez, Smart Mater. Struct., 2010, 19, 065010.

21 H. R. Gallantree, IEE Proc., Part I: Solid-State Electron Devices, 1983, 130, 219-224.

22 H. S. Nalwa, Ferroelectric Polymers: Chemistry, Physics, and Applications, Marcel Dekker, New York 1995.

23 T. T. Wang, J. M. Herbert and A. M. Glass, The Applications of Ferroelectric Polymers, Chapman and Hall, New York, 1988.
24 A. Issa, M. A. Al-Maadeed, A. S. Luyt, M. Mrlik and M. K. Hassan, J. Appl. Polym. Sci., 2016, 133, 2-13.

25 A. Al-Saygh, D. Ponnamma, M. A. Al Maadeed, P. Vijayan, A. Karim and M. K. Hassan, Polymers, 2017, 9, 33.

26 Y. Zhao, Q. Liao, G. Zhang, Z. Zhang, Q. Liang, X. Liao and Y. Zhang, Nano Energy, 2015, 11, 719-727.

27 N. Jia, Q. Xing, G. Xia, J. Sun, R. Song and W. Huang, Mater. Lett., 2015, 139, 212-215.

28 P. Talemi, M. Delaigue, P. Murphy and M. Fabretto, ACS Appl. Mater. Interfaces, 2015, 7, 8465-8471.

29 V. Cauda, S. Stassi, K. Bejtka and G. Canavese, ACS Appl. Mater. Interfaces, 2013, 5, 6430-6437.

30 Y. Kim, Y. Xie, X. Wen, S. Wang, S. J. Kim, H. Song and Z. L. Wang, Nano Energy, 2015, 14, 77-86.

31 M. S. Sebastian, A. Larrea, R. Gonçalves, T. Alejo, J. L. Vilas, V. Sebastian, P. Martins and S. Lanceros-Mendez, RSC Adv., 2016, 6, 113007-113015.

32 S.-H. Kim, J.-W. Ha, S. G. Lee, E.-H. Sohn, I. J. Park, H. S. Kang and G.-R. Yi, Langmuir, 2019, 35, 8816-8822.

33 B.-E. E. Mohajir and N. Heymans, Polymer, 2001, 42, 56615667.

34 V. Sencadas, R. Gregorio and S. Lanceros-Méndez, J. Macromol. Sci., Part B: Phys., 2009, 48, 514-525.

35 B. Li, C. Xu, J. Zheng and C. Xu, Sensors, 2014, 14, 9889-9899. 36 Z.-M. Dang, S.-S. You, J.-W. Zha, H.-T. Song and S.-T. Li, Phys. Status Solidi, 2010, 207, 739-742.

37 J. H. Li, X. S. Shao, Q. Zhou, M. Z. Li and Q. Q. Zhang, Appl. Surf. Sci., 2013, 265, 663-670.

38 J. Compton, D. Kranbuehl, G. Martin, E. Espuche and L. David, Macromol. Symp., 2007, 247, 182-189.

39 X. Cai, T. Lei, D. Sund and L. Lin, $R S C A d v$., 2017, 7, 1538215389.

40 D.-M. Ren, H.-K. Huang, Y. Yu, Z.-T. Li, L.-W. Jiang, S.-M. Chen, K.-H. Lam, B. Lin, B. Shi, F.-A. He and H.-J. Wu, J. Nanosci. Nanotechnol., 2018, 18, 3274-3282.

41 P. Martins, A. C. Lopes and S. Lanceros-Mendez, Prog. Polym. Sci., 2014, 39, 683-706.

42 M. Benz, W. B. Euler and O. J. Gregory, Macromolecules, 2002, 35, 2682-2688.

43 H. Liow, X. Lu, C. F. Tan, K. H. Chan, K. Zeng, S. Li and G. W. Ho, Small, 2018, 14, 1702268.

44 C. Tsonos, N. Pandis, D. Soin, E. Sakellari, S. Myrovali, A. Kripotou, A. Kanapitsas and E. Siores, eXPRESS Polym. Lett., 2015, 9, 1104-1118.

45 P. Martins, C. M. Costa and S. Lanceros-Mendez, Appl. Phys. A, 2011, 103, 233-237.

46 J. Liu, X. Lu and C. Wu, Membranes, 2013, 3, 389-405.

47 R. Gregorio Jr and M. Cestari, J. Polym. Sci., Part B: Polym. Phys., 1994, 32, 859-870. 